\title{
Underground Cable Fault Detection
}

\author{
Roshani Shingrut \\ Electrical Engineer \\ Vishwaniketan IMEET Kharagpur \\ Dakshata Mokal \\ Electrical Engineer \\ Vishwaniketan IMEET Kharagpur
}

\author{
Shubham Shelar \\ Electrical Engineer \\ Vishwaniketan IMEET Kharagpur \\ Shekar Mhatre \\ Electrical Engineer \\ Vishwaniketan IMEET Kharagpur
}

\author{
Dr. Sharvari Sane \\ HOD. Electrical Engineer \\ Vishwaniketan IMEET Kharagpur
}

\begin{abstract}
Underground cables have been widely used with the development of power system grid .Underground cables are prone to a wide variety of faults due to underground conditions, wear and tear, rodents. Detecting fault source is difficult because entire line is to be dug in order to check fault at cable line. The repairmen know exactly which part has fault and only that area is to be dug to detect the fault source. Thus it saves a lot of time, money and allows to service underground cable lines faster. The aim of this project is to determine the distance of underground cable fault from base station in $\mathrm{Km}$.
\end{abstract}

Keywords- Underground, Fault, Detect, Money, Repairman.

\section{INTRODUCTION}

In this project we proposed a fault localization model for the underground cable lines with Arduino. The purpose of this paper is to determine the distance from the base station's underground cable fault in kilometres. In this project we used a simple concept of ohm's low. When a fault occurs in the system the distance located on liquid crystal display (LCD). Until the last decade, cables were designed to be placed above the head and, at present, there is no underground cable that is higher than the previous method. adverse weather conditions such as storms, snow, torrential rains and pollution does not affect on underground lines But when a fault occurs in underground lines it is difficult to locate the fault in underground cable. We will find the exact location of the fault. Now the world has become digitized so, the project is to detect exact location of the fault in digital form. Underground cabling system is a more common practice in many urban areas. Although the fault occurs for some reason, at that time, the repair process for this particular cable is difficult because of not knowing the exact location of the cable breakdown. Fault in cable can be classified in two groups: Open circuit fault:-In open circuit fault there is no current because there no conducting complete loop for current flowing that is $\mathrm{I}=0$.in this fault supply voltage is equal to the output voltage. Open circuit fault is better than short circuit fault.. Short circuit fault:- In this fault output voltage is zero but current is same Further short circuit fault can be categorized in two types: Symmetrical fault:- In this fault :equal lead current and equal phase shift. Unsymmetrical fault: - In this fault magnitude of current is not equal \& phase shifting is not equal by 120 degree. Terminal method:- in this method used to detect the fault location in underground lines without any effort This method used to locate the type of circuit occurs; the voltage drop varies with the default length on the cable, as the current varies. A plurality of resistors is used to represent the cable and a DC voltage is supplied at one end and the defect detected by detecting the voltage variation the defect area to accelerate the tracking of the buried cable.

\section{LITERATURE SURVEY}

\section{Presented Design \& Implementation Of Fault Identification In Underground Cables Using IOT .}

This project is to determine the distance of underground cable fault from the base station in kilometres and displayed over the internet. Underground cable system is a common followed in major areas in Metro cities. While a fault occurs for some reason, at that time the fixing process related to that particular cable is difficult due to exact unknown location of the fault in the cable. This Technology is used to find out the exact location of the fault and to send data in graphical format to our website using a GSM module at the same time it display on the LCD screen.

The project uses the standard theory of Ohms law, i.e., when a low DC voltage is applied at the feeder end through a series resistor (Cable lines), then the current would vary depending upon the location of the fault in the cable as the resistance is proportional to the distance. In case there is a short circuit (Line to Ground), the voltage across series resistors changes according to the resistance that changes with distance. This is then fed to an ADC to develop precise digital data which the programmed microcontroller of the 8051 family displays in kilometres.

\section{Presented Analysis of Underground Cable Fault Distance Locator.}

Underground cables are prone to a wide variety of faults due to underground conditions, wear and tear, rodents etc. Also detecting fault source is difficult and entire line is to be dug in order to check entire line and fix faults. So here we propose cable fault detection over IOT that detects the exact 
fault position over IOT that makes repairing work very easy. The repairmen know exactly which part has fault and only that area is to be dug to detect the fault source. This saves a lot of time, money and efforts and also allows to service underground cables faster. We use IOT technology that updates the monitored fault information to internet. The system detects fault with the help of potential divider network laid across the cable. Whenever a fault gets created at a point shorting two lines together, a specific voltage gets generated as per the resistors network combination. This voltage is sensed by the microcontroller and is updated to the user. The information conveyed to the user is the information regarding faults detection.

\section{Arduino Based Underground Transmission Cable Fault Location System.}

The transmission line fault location requires intense human effort and resources. Typically this process is time consuming and while digging the cable there is a risk of damaging the insulation .This paper provides a simple and safe alternative by automating the process of fault detection and location. The project uses the simple concept of OHMs law where a low DC voltage is applied at the feeder end through a series resistor.

The current would vary depending upon the length of fault of the cable in case there is a short circuit of $L L$ or $3 \mathrm{~L}$ or $\mathrm{LG}$ etc. The series resistor voltage droop changes accordingly which detects the exact location of the fault for process of repairing that particular cable. The proposed system finds the exact location of the fault. This system uses an Arduino micro controller kit and a rectified power supply. Here the current sensing circuits made with a combination of resistors are interfaced to Arduino micro controller kit to help of the internal ADC device for providing digital data to the microcontroller representing the cable length in kilometres.

The fault creation is made by the set of switches. The relays are controlled by the relay driver. A 16x2 LCD display connected to the microcontroller to display the information. In case of short circuit, the voltage across series resistors changes accordingly, which is then fed to an ADC to develop precise digital data to a programmed Arduino micro controller kit that further displays exact fault location from base station in kilometres. The project in future can be implemented by using capacitor in an AC circuit to measure the impedance which can even locate the open circuited cable.

Presented Underground Cable Fault Detector Using GSM . The main aim of the project is to detect and locate the fault in underground cable. In the urban areas, the electrical cable runs in undergrounds instead of overhead lines. Whenever the fault occur the repairing process becomes difficult. It is very difficult to identify the exact location of the fault in underground power cable line. This project will ensure a shorter response time for technical crew to rectify these faults . Fault occur due to short circuit fault, low voltage fault, high voltage fault. Previously proposed technique is used to identify short circuit fault only. This project is used to detect not only detect short circuit fault but also detect, low voltage fault, high voltage fault. The system developed here works on the basis of Ohm's law. The proposed technique is used not only for identification but also it is used to send the detail information about the fault to the authority using GSM and also it cut the power supply on that particular location for the security of the people. It also used to display the type of the fault in LCD display. Whenever a fault occurs in a cable the buzzer produces the sound to alert and to take an immediate action

\subsection{Underground Cable Fault Detection using Raspberry Pi and Arduino.}

This paper proposes fault location model for underground power cable using raspberry pi and the Internet of Things which is based on the internet, which means the information will be transferred through the internet access. The aim of this method is to determine the distance of underground cable fault from base station in kilometres and also find the location of that faulty place. This paper uses the simple concept of Current Transformer Theory (CT Theory). When any fault like short circuit occurs, voltage drop will vary depending on the length of fault in cable; since the current varies Current Transformer is used to calculate the varying current. The signal conditioner manipulates the change in voltage and a microcontroller is used to make the necessary calculations so that the fault distance is displayed by IOT devices. These fault details are after sent to any access point through the internet and displayed.

\section{PROCEDURE}

- The circuit consists of a power supply, 4 line display, arduino and resistance measurement circuit. To induce faults manually in the kit, fault switches are used. About 12 fault switches are used which are arranged in three rows with each row having 4 switches. The 3 rows represent the 3 phases namely $\mathrm{R}, \mathrm{Y}$ and $\mathrm{B}$. The fault switches have 2 positions-No fault position(NF) and fault position(F).Main component of the underground cable fault detection circuit is low value resistance measurement. It is constructed using a constant current source of 100 mAmps. It can measure very low value resistance as the cables have around $0.01 \mathrm{Ohm} / \mathrm{meter}$ resistance. For 10meter cable resistance becomes 0.1 Ohm. This circuit can measure resistance up 50 Ohm, Maximum cable length it can check up to 4 kilometres.

- So starting from the reference point 3 sets of resistances are placed in series. These 3 sets of resistances represent the three phases and the neutral. Short circuit faults, Symmetrical and unsymmetrical faults can be determined by this method. This project uses three set of resistances in series (ie)R10R11-R12R12,R17-R16-R14R21,R20-R19-R18-R25 one for each phase 
.Each series resistor represents the resistance of the underground cable for a particular distance and so here four resistances in series represent $1-3 \mathrm{kms}$. Value of each resistance is $10 \mathrm{k} \Omega$.

- One relay for each phase R,Y and B as three relays are used and the common points of the relays are grounded and the NO points are connected to the inputs of R17,R21 and R25 and being the three phase cable input. As supply needed for the relays is higher than that of the arduino, Relay driver is used to boost the supply and provide it to the relays. A $230 \mathrm{~V}$ AC supply is applied to the transformer from where it is stepped down to $12 \mathrm{~V}$ AC From the transformer the alternating current gets converted into direct current when it passes through a Bridge wave rectifier.The $12 \mathrm{~V}$ DC then goes to the voltage regulator where it gets converted from $12 \mathrm{~V}$ DC to $5 \mathrm{~V}$ DC Voltage regulator is used also converts the variable Dc supply into constant DC supply. This $5 \mathrm{~V}$ $\mathrm{DC}$ is used to supply power to the arduino and the LCD Power supply to the LCD is given from the voltage regulator.

- When fault is induced by operating any of the 12 switches (to $F$ position), they impose conditions like LG,LL,LLG fault as per the switch operation. As a result of the fault, there is a change in voltage value. This voltage value measured across the resistance is fed to the ADC of the Arduino. Using this value, the arduino computes the distance. Finally the distance of the fault from the base station is displayed in kilometre.

\section{BLOCK DIAGRAM}

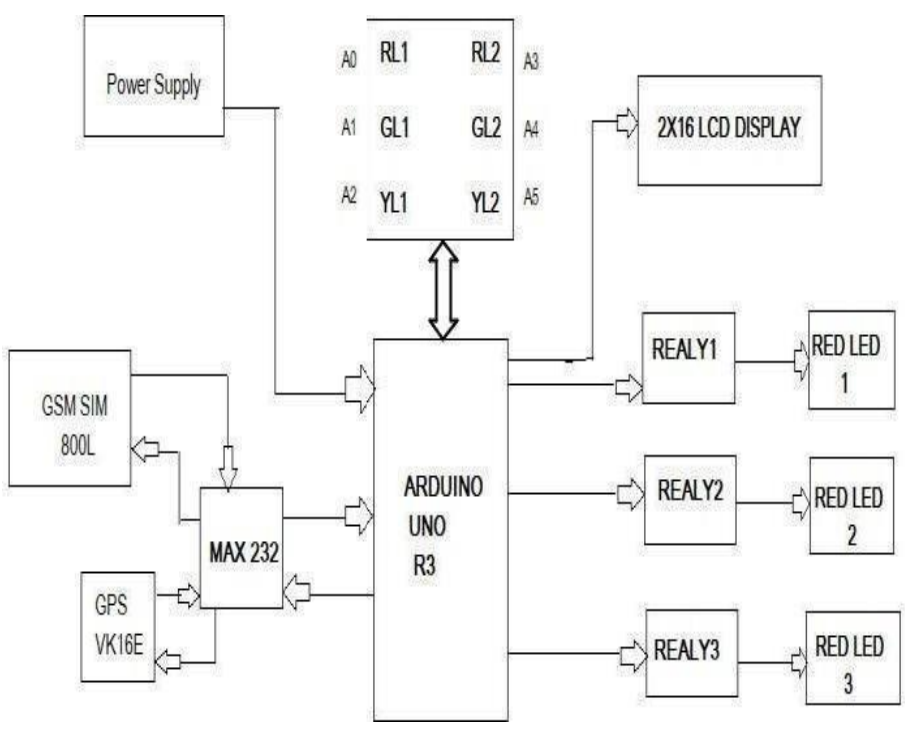

Fig-1: Block Diagram

\section{COMPONENT RATINGS}

\begin{tabular}{|c|c|}
\hline COMPONENTS & RATINGS \\
\hline Diode & IN4007 \\
\hline Capacitor & $22 \mathrm{pF}$ \\
\hline Resistor & $1 \mathrm{k} \Omega$ \\
\hline Resistor & $470 \Omega$ \\
\hline Resistor & $10 \mathrm{k} \Omega$ \\
\hline LED & 3 \\
\hline BJT & BC547 \\
\hline Arduino & UNO \\
\hline Crystal & $16 \mathrm{MHZ}$ \\
\hline Relay & $12 \mathrm{~V}$ \\
\hline Push buttons & \\
\hline IC base & \\
\hline PCB & 2 METERS \\
\hline Wires & $12 \mathrm{~V}$ \\
\hline Transformer & \\
\hline
\end{tabular}

\section{SOFTWERE REQIREMENTS}

\subsection{Proteus ISIS [System Design]}

The Proteus Design Suite is an Electronic Design Automation (EDA) tool including schematic capture, simulation and PCB Layout modules. It is developed in Yorkshire, England by Lab centre Electronics Ltd with offices in North America and several overseas sales channels. The software runs on the Windows operating system. The micro-controller simulation in Proteus works by applying either a hex file or a debug file to the microcontroller part on the schematic. It is then cosimulated along with any analog and digital electronics connected to it. This enables it's used in a broad spectrum of project prototyping in areas such as motor control, temperature control and user interface design.

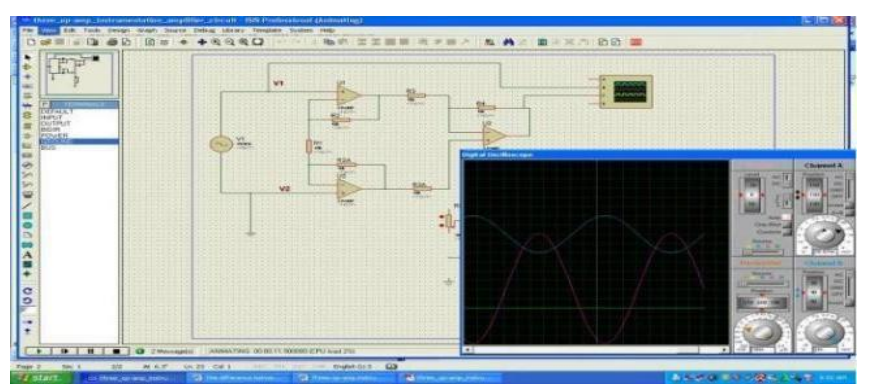

\subsection{Proteus Ares [PCB Design]}

High performance net list based PCB design package perfectly complements our powerful schematic capture software and features both automatic component placement and a truly world class shape based auto-router. Fully integrated user friendly advance PCD design software.

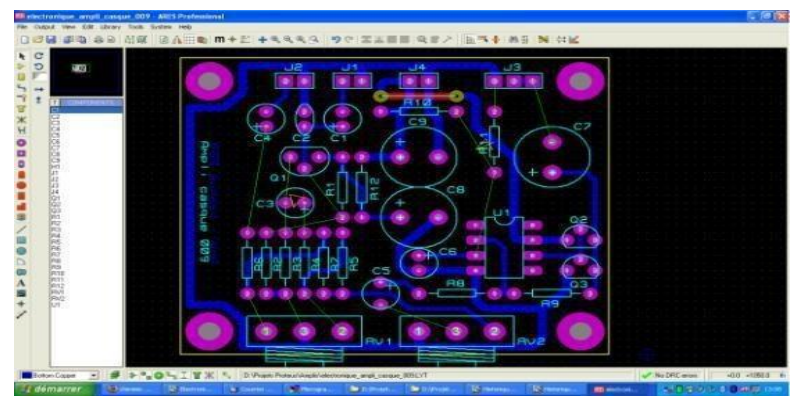




\section{ADVANTAGES}

- Less maintenance

- It has higher efficiency

- Less fault occur in underground cable This method is applicable to all types of cable ranging from $1 \mathrm{kv}$ to $500 \mathrm{kv}$

- It can detect other types of cable fault such as Short circuit fault, cable cuts,

- Resistive fault, Sheath faults, Water trees, Partial discharges.

\section{FUTURE SCOPE}

In this project we detect the exact location of short circuit fault in the underground cable from feeder end in $\mathrm{km}$ by using arduino. In future, this project can be implemented to calculate the impedance by using a capacitor in an AC circuit and thus measure the open circuit fault.

\section{REFERENCES}

[1] "Detection and localization of cable faults by time and frequency domain measurements", Qinghai Shi, Troeltzsch U, Kanoun O. Conf. Systems and Signals and Devices, 7th International conference, Amman.2010; 1-6

[2] "Underground Cable Fault Location” ,B. Clegg. New York: McGraw- Hill, 1993.

[3] "A line to ground fault location algorithm for underground cable system”, M.-S. Choi, D.-S. Lee , and X. Yang. KIEE Trans. Power Eng., pp. 267-273, Jun. 2005.

[4] "Computerized underground cable fault location expertise", E. C. Bascom in Proc. IEEE Power Eng. Soc.General Meeting, Apr. 10-15, 1994, pp. 376-382.J.

[5] “A Treatise on Electricity and Magnetism, 3rded, vol. 2", Clerk Maxwell. Oxford: Clarendon, 1892, pp.68-73.

[6] "Detection of incipient faults in distribution underground cables",T. S. Sidhu and Z. Xu, IEEE Trans. Power Del., vol. 25, no. 3, pp. 1363-1371, Jul. 2010.

[7] "Detection of Incipient Faults in Distribution Underground Cables", IEEE Transactions on Power Delivery, Tarlochan S. Sidhu, ZhihanXu, Vol. 25, NO. 3, JULY 2010.

[8] "Locating Underground Cable Faults: A Review and Guideline for New Development", Md. Fakhrul Islam, Amanullah M T Oo, Salahuddin. A. Azad1. 2013 IEEE. 